\title{
Use of low volume, high effort resistance training to manage blood pressure in hypertensive patients inside a public hospital: a proof of concept study
}

\author{
Camila Simões Seguro (1), Ana Cristina Silva Rebelo (2), Anderson Garcia Silva (1), \\ Matheus Malaquias Alves dos Santos (1), John Sebastião Cardoso (1), Valéria \\ Apolinário (3), Paulo Cesar Veiga Jardim (3), Paulo Gentil $(1,3)$
}

(1) Faculty of Physical Education and Dance, Federal University of Goiás, Goiânia, Brazil; (2) Institute of Biological Sciences, Federal University of Goiás, Goiânia, Brazil; (3) Hypertension League, Federal University of Goiás, Goiânia, Brazil

This article is distributed under the terms of the Creative Commons Attribution Noncommercial License (CC BY-NC 4.0) which permits any noncommercial use, distribution, and reproduction in any medium, provided the original author(s) and source are credited.

\begin{abstract}
Physical exercise has been shown to have an important role in the prevention and treatment of arterial hypertension. However, the general exercise recommendations are time consuming, which might be detrimental to exercise adoption. Based on this, minimal doses of exercise have been suggested as an alternative approach and this report investigates the feasibility and effects of low volume and high effort resistance training for hypertensive patients in a hospital setting. This is a pilot non-randomized prospective study where 15 sedentary hypertensive patients (11 women and 4 men) performed 24 resistance training sessions over 12 weeks at a public hospital. The resistance training sessions consisted of two sets of four exercises, with a rest interval of two minutes between sets. Systolic blood pressure (SBP) and diastolic blood pressure (DBP) were measured 10 minutes before and 10 minutes after each training. No injuries or intercurrence were reported during the study. SBP decreased significantly when compared the first and last sessions, when the measures were performed at rest $(152 \pm 16 \mathrm{mmHg}$ vs. $122 \pm 9 \mathrm{mmHg}$ vs, $\mathrm{p}<0.05)$, and after $(137 \pm 13 \mathrm{mmHg}$ vs. $115 \pm 5 \mathrm{mmHg}, \mathrm{p}<0.05)$ the resistance training session. Similarly, DBP also decreased significantly when the values from the last session were compared with the first session, when measured at rest $(83 \pm 14 \mathrm{mmHg}$ vs $73 \pm 9 \mathrm{mmHg}, \mathrm{p}<0.05)$. Low volume and high effort resistance training seems to be a feasible non-pharmacological strategy to help controlling blood pressure in hypertensive patients within a hospital.
\end{abstract}

Key Words: exercise is medicine; aging; cardiopathy; diabetes; resistance exercise; strength training.

Eur J Transl Myol 31 (1): 9547, 2021 doi: 10.4081/ejtm.2021.9547

\begin{abstract}
Arterial hypertension is the most common chronic noncommunicable disease among the elderly and represents one of the greatest challenges in public health. ${ }^{1}$ Most guidelines recommend lifestyle modifications (e.g., increased physical activity, smoking cessation, moderate alcohol consumption, improved dietary choices) as an important strategy to prevent and manage hypertension. ${ }^{2,3}$ In this sense, physical exercise, such as aerobic and resistance exercise, is considered one of the most important non-pharmacological treatments. ${ }^{2}$ Specifically regarding resistance training there is evidence that it can prevent and treat high blood pressure at all stages. ${ }^{4}$ However, the guidelines for hypertensive patients are not consensual. ${ }^{2,5,6}$ One important aspect of exercise prescription is time commitment, since lack of
\end{abstract}

time is an important barrier for exercise adoption. ${ }^{7}$ In this regard, low volume and high effort resistance training (i.e. one to two sets of 8-12 repetitions of 4 exercises, taking approximately 20 minutes per session) has gained notoriety for improving health and functional parameters, especially in older people. ${ }^{8,9}$ In a case study, Seguro et al. reported that only 40 minutes of exercise per week was sufficient to promote positive cardiovascular and metabolic changes in a hypertensive and diabetic patient. ${ }^{10}$ A similar approach adopted by Costa et al. ${ }^{9}$ produced functional benefits in older women. Therefore, the use of such strategy might be useful as an adjunct in the treatment of hypertensive patients, especially considering that resistance training might reduce resting blood pressure, ${ }^{11,12}$ and that muscle strength is associated 


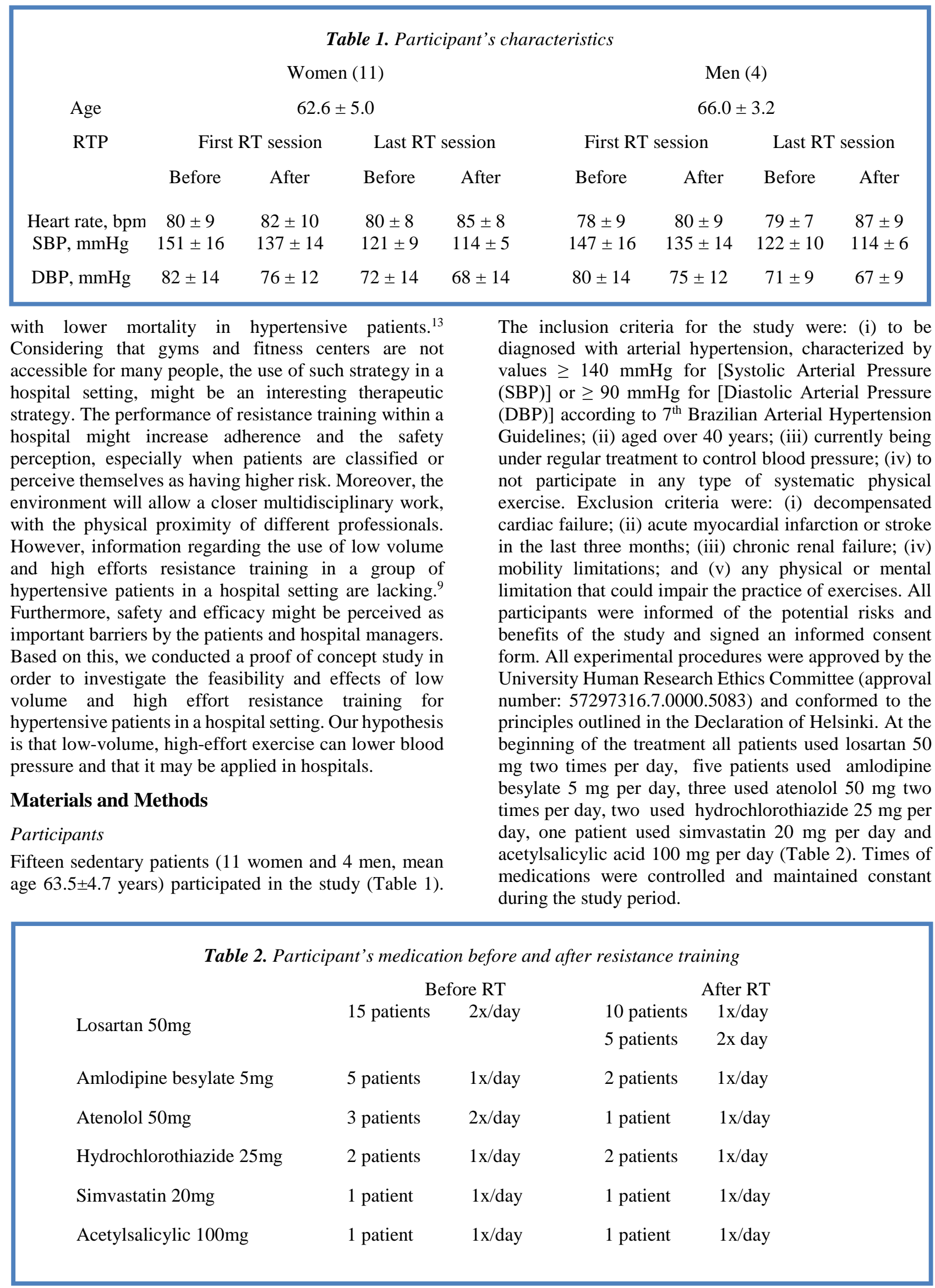




\section{Study Design}

The study was carried out at a public hospital with ambulatory visits at the Physical Education department and the patients were referred by an accredited cardiologist. All sessions were performed in an exercise room inside the hospital. The room has $120 \mathrm{~m}^{2}$ and contained one leg press $45^{\circ}$, one pulldown machine, one cable seated row, two bars, one dumbbell kit (2 to $10 \mathrm{~kg}$ ) and weight plates. Each patient performed 24 resistance training sessions over 12 weeks, with at least 48 hours between them. HR, SBP and DBP were measure before and after resistance training. All patients were instructed to report any change in medication during the study period and this was confirmed by their physicians. The resistance training sessions lasted approximately 20 minutes. Participants were instructed to maintain their usual diet during the study. During the study, the participants were constantly monitored for injuries and any possible negative outcome associated with the intervention.

\section{Blood pressure and heart rate}

SBP, DBP and HR were measured immediately before and 10 minutes after each resistance training session using a validated digital blood pressure monitor (OMRON, HEM-705CP, China). Before each measure, the patient remained seated for 10 minutes. The procedures followed the 7th Brazilian Arterial Hypertension Guidelines ${ }^{14,15}$. The comparisons involved the measures performed in first and last training session (i.e. pre training values at the first training session vs. pre training values at the last training session; post training values at the first training session vs. post training values at the last training session). The standard error of the measure and intraclass correlation coefficient for SBP, DBP and HR were $3.7 \mathrm{mmHg}$ and 0.98, $4.6 \mathrm{mmHg}$ and 0.84 , and $3.1 \mathrm{bpm}$ and 0.94 , respectively.

\section{Resistance Training intervention}

The participants performed resistance training two times per week, separated by at least 48 hours, between 8 and
10 a.m. The participants had the possibility of training in different days; therefore, if the lost a session, they could perform it in the next available day. The research staff maintained constant contact with all the participants through telephone and instant messages in order to motivate adherence and monitor adverse events. All resistance training sessions were performed following a minimum dose approach, ${ }^{16}$ and were individually supervised by certified and qualified physical education professionals. ${ }^{17}$ The resistance training sessions were composed of four multi joint exercises (leg press, lat pulldown, deadlift and incline dumbbell bench press). ${ }^{18}$ Two sets were performed for each exercise with twominutes rest interval between sets. During the first four resistance training sessions the participants performed 10-12 repetitions to volitional fatigue. After the fifth resistance training session, patients performed 6-9 repetitions to momentary muscle failure with rests of two minutes between sets, as defined by Steele et al. ${ }^{16,19}$ The participants were instructed to maintain two seconds in the concentric and eccentric phase, without rest in the transition phase. Workloads were adjusted whenever necessary to maintain the target range of repetitions. ${ }^{8,10}$

\section{Statistical Analysis}

According to the Shapiro-Wilk test, all variables presented a normal distribution ( $p>0.05$ ), except SBP measured after the first and last resistance training session and DBP measured after the first resistance training session. Student's paired t-tests were used to compare variables with normal distribution and Wilcoxon test to compare those without normal distribution. Descriptive statistics was used to describe the mean and standard deviation of participants' age. All statistical analyses were performed with the GraphPad Prism software (version 5.0, San Diego, CA, USA). The significance level was set $\mathrm{p} \leq 0.05$.

\section{Results and Discussion}

All patients initially selected concluded the study and no injuries were reported. There were no differences in HR when comparing pre and post intervention values, either

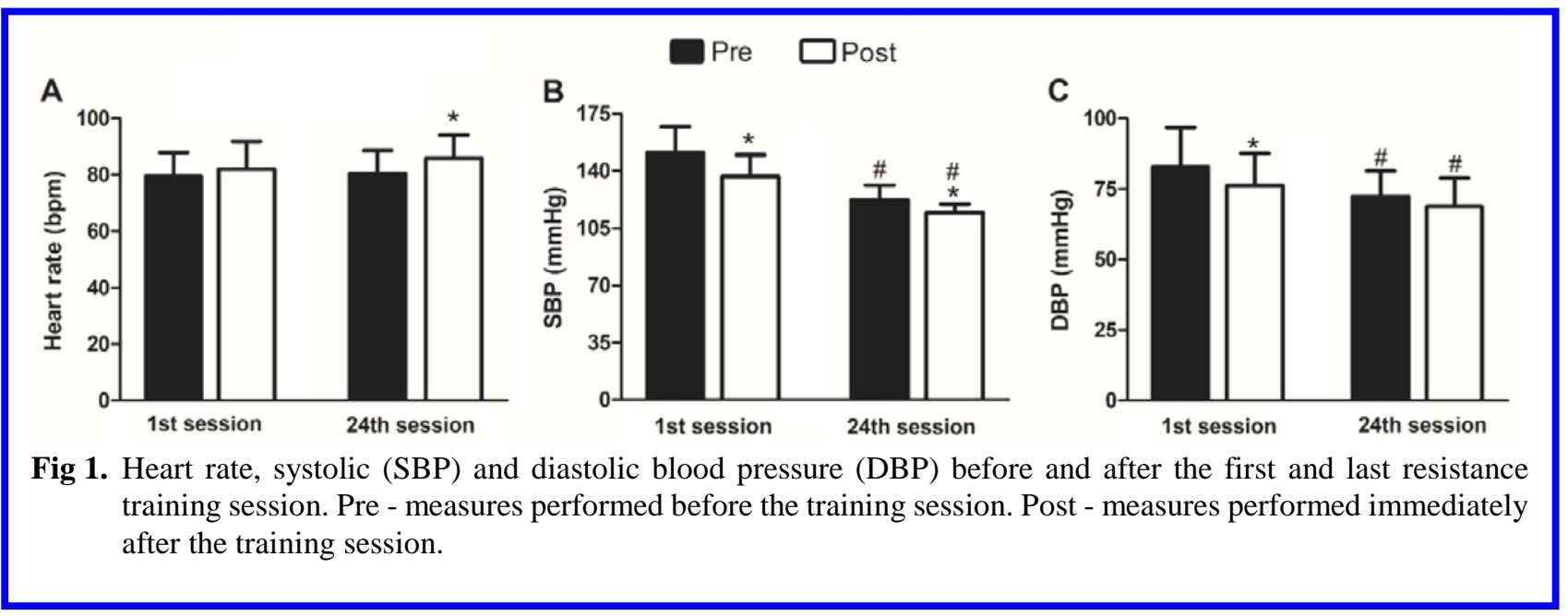




\section{Resistance training to treat blood pressure in a hospital}

Eur J Transl Myol 31 (1): 9547, 2021 doi: 10.4081/ejtm.2021.9547

measured before or after training session. SBP measured before (SBPpre $\Delta: 18.7 \pm 8.0 \%[29 \pm 15 \mathrm{mmHg}]$ ) and after (SBPpost $\Delta: 15.4 \pm 9.0 \%[22 \pm 15 \mathrm{mmHg}]$ ) the last resistance training session decreased significantly from the corresponding values in the first resistance training session. DBP measured before (DBPpre $\Delta: 11.2 \pm 12.1 \%$ $[10 \pm 11 \mathrm{mmHg}])$ and after (DBPpost $\Delta: 8.5 \pm 15.9 \%$ [7 $\pm 13 \mathrm{mmHg}]$ ) the last resistance training session decreased significantly from the corresponding values in the first resistance training session (Figure 1). A posteriori calculation revelated that the observed power was $>0.99$ for both SBPpre and SBPpost, 0.71 for DBPpre and 0.6 for DBPpost (Figure 2). During the study period eight patients reported dizziness and low blood pressure, which lead the physician to adjust the patients' medication. At the end of the 12 weeks, eight patients reduced the amount of losartan to once daily, three decreased amlodipine, two decreased atenolol and the patient who used simvastatin had the medication suspended.

The purpose of this study was to test the effects of low doses of high effort resistance training performed inside a hospital. The study showed that 20-minute sessions of resistance training carried out over 12 weeks, 2 times per week, were able to significantly reduce SBP and DBP in hypertensive adults with $100 \%$ adherence and no report of injuries. Whilst medication reduction was not the primary endpoint of the study, it is interesting to note that such reductions occurred with a concomitant decrease in the amount of medications used. The volunteers were taking medications to control hypertension for more than 5 years and their records showed a progression or stability in the amount and dose of medication. However, during the study, many patients have reported sleepiness and discomfort in daily activities, which lead the physician to reevaluate the anti-hypertensive medication prescription. The dose Losartan fell by half in two-thirds of the patients, three decreased amlodipine and atenolol decreased in two patients. Although previous metaanalysis showed that resistance training is able to reduce resting blood pressure, ${ }^{11}$ the results of the studies are not consensual. In this regard, our findings are contrary to a previous study published by Gomes in which hypertensive patients performed seven exercises (bench press, leg press, seated row, knee extension, arm barbell curls, leg curl, front elevation and abduction the hip) for 12 weeks. ${ }^{20}$ The exercises were performed with three sets of 10 repetitions and two-minute interval between sets, resulting in a duration of approximately 40 minutes. Different form our findings, there were no changes in resting blood pressure. ${ }^{20}$ The divergence between the results is not clear. Traditionally, 150 minutes of moderate-intensity physical activity or 75 minutes of vigorous intensity physical activity are recommended as non-pharmacological treatments for hypertension., 2,6,21 However, our study shows that small doses of high effort resistance training ( $\sim 40$ minutes per week) were able to significantly reduce blood pressure. The reductions in blood pressure found in our study may be clinically relevant for hypertensive people, since it has been shown that the decrease of $20 \mathrm{mmHg}$ on systolic and $10 \mathrm{mmHg}$ in diastolic blood pressure represents a $50 \%$ decrease in mortality risk by stroke, ischemic disease and other vascular diseases. ${ }^{22,23}$

The choice of small number of repetitions $(<10)$ was for safety reasons, since it promotes lower acute increases in blood pressure, HR, double product, ${ }^{24-26}$ and promotes better autonomic modulation than performing a higher number of repetitions. ${ }^{27}$ Resistance training sessions were composed of four multi-joint exercises, with two sets for each exercise, two minutes interval between sets and a speed of two seconds in both eccentric and concentric phase. Multi-joint exercises were selected due to the evidence that they are more efficient in improving general physical fitness, maximal oxygen uptake and muscular strength than single joint exercises, ${ }^{18}$ and there is also evidence that the addition of single joints exercises to a multi-joint exercise program does not lead to morphological or functional benefits. ${ }^{28,30}$ Movement velocity was controlled to improve movement quality and because previous studies showed that higher speed resulted in higher blood pressure responses. ${ }^{31}$ In relation
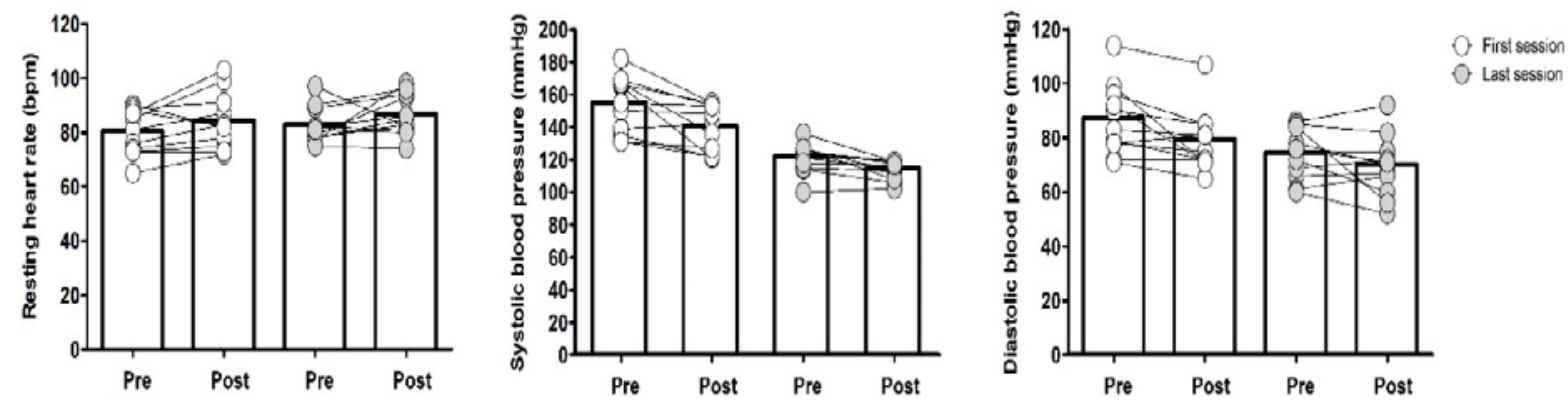

Fig 2. Heart rate, systolic (SBP) and diastolic blood pressure (DBP) before and after the first and last resistance training session. Pre - measures performed before the training session. Post - measures performed immediately after the training session. 
to training volume, there is evidence that an increase in the number of sets does not bring additional functional benefits to older people. ${ }^{32,33}$ Therefore, we opted to perform only two sets two times a week in order to adhere to the minimum dose approach mentioned previously. ${ }^{8,9}$ These results might be applicable in a hospital setting in a multidisciplinary perspective because of the constant need to monitor the patients and adjust the medications. The present results can also serve as a parameter for future research, since most guidelines suggest relatively high doses of resistant training concomitant to aerobic training for the management of hypertension. ${ }^{2,6,21,34}$ Our findings suggest the possibility of a non-pharmacological intervention as an aid in the management of arterial hypertension, with a considerably less time commitment than indicated by most guidelines. Considering the high prevalence of hypertension, it would be interesting to consider the inclusion of low doses of physical exercises as a first line of treatment in clinical environments, such as clinics and hospitals, this might increase adherence and optimize the occupation of the facilities. It is important to note that the patients have been previously advised to participate in regular physical activity over the previous years, since this is a standard procedure in the hospital; however, none have spontaneously participated in an exercise program before the study. Therefore, we believe that offering this possibility inside the hospital might have important practical applications.

This study has some important limitations. First, there was no rigid dietary control. Although, patients were advised to not change their diets, we are not able to confirm if they followed the recommendations. However, it is worth noting that the volunteers have been receiving the same nutritional counselling for the previous years, so it's unexpected that there have been relevant modifications after the beginning of the study. Another important methodological limitations are the small and mixed sample and the absence of a control group; however, for institutional and ethical reasons the treatment option was offered to all participants. However, as we do not have a non-exercise control group, we are unable to provide an estimation of sample size for future clinical trials. A non-exercise control group would be necessary to estimate the "true effect size" after account for random error. In addition, the participants were stable for years, and there were no changes in their medications prior to the study, therefore it is expected that the reported effects were due to the training protocol. It is important to note that patients were under treatment in a reference center, which makes it safer to apply high intensity workouts. In cases of higher risk as in less controlled patients, it is important to analyze the strategies to be applied individually. In addition to these main limitations, it should be noted that the patients were predominantly women.

We conclude that low volume and high effort resistance training is a feasible non-pharmacological strategy to control blood pressure in hypertensive patients within a hospital. It is important to note that the intervention was performed in litle space and with minimum equipments that bring wide perspectives of general application.

\section{List of acronyms}

DBP - diastolic blood pressure

HR - heart rate

SBP - systolic blood pressure

\section{Authors contributions}

CS and PG designed the intervention; CS, ACR, PCVJ and PG performed the analysis; CS, MMAS, JSC, VA and PG conduced and supervised the intervention; CS, ACR, MMAS, JSC, VA, PCVJ and PG writing-review and editing; All authors have read and agreed to the published version of the manuscript..

\section{Acknowledgments}

The authors would like to thank all the voluntary participants and the mangers of Hospital da Clínicas de Goiania, Brasil.

\section{Funding}

PG received a Research Grand from CNPq (304435/2018-0).

\section{Conflict of Interest}

The authors declare no competing interests.

\section{Ethical Publication Statement}

We confirm that we have read the Journal's position on issues involved in ethical publication and affirm that this report is consistent with those guidelines.

\section{Corresponding Author}

Paulo Gentil, PhD, Human Movement Assessment Laboratory, Faculty of Physical Education and Dance, Federal University of Goiás (UFG), Brasil.

ORCID iD: 0000-0003-2459-4977

E-mail: paulogentil@hotmail.com

\section{E-mail and ORCID of co-authors}

Camila Simões Seguro: miaseguro@hotmail.com

ORCID iD: 0000-0001-5898-9833

Ana Cristina Rebelo: anacristina.silvarebelo@gmail.com

ORCID iD: 0000-0002-9214-5025

Anderson Garcia Silva: andersongarciasilva@hotmail.com

ORCID iD: 0000-0002-6550-3069

Matheus Malaquias Alves dos Santos:

ORCID iD: None matheus.edfi@gmail.com

John Sebastião Cardoso: johnscsilva@gmail.com ORCID iD: 0000-0002-7018-5173

Valéria Apolinário: valeria.fisiohc@yahoo.com ORCID iD: None

Paulo Cesar Veiga Jardim: fvjardim.ufg@gmail.com ORCID iD: 0000-0002-5333-013X 


\section{References}

1. Malachias MVB, Ferreira S Filho, Souza WKSB, Ribeiro JM, Miranda RD, Jardim TSV. 7th Brazilian Guideline of Arterial Hypertension: Chapter 11 - Arterial Hypertension in the elderly. Arq Bras Cardiol. 2016 Sep;107(3 Suppl 3):64-66. doi: 10.5935/abc.20160161.

2. Malachias MVB, Franco RJ, Forjaz CLM, Pierin AMG, Gowdak MM, Klein MRST, Matsudo V. 7th Brazilian Guideline of Arterial Hypertension: Chapter 6 - Non-pharmacological treatment. Arq Bras Cardiol. 2016 Sep;107(3 Suppl 3):30-34. doi: 10.5935/abc.20160156.

3. Malachias M, Plavnik FL, Machado CA, Malta D, Scala LCN, Fuchs S. 7th Brazilian Guideline of Arterial Hypertension: Chapter 1 - Concept, Epidemiology and Primary Prevention. Arq Bras Cardiol. 2016 Sep;107(3 Suppl 3):1-6. doi: 10.5935/abc.20160151.

4. Pescatello LS, Buchner DM, Jakicic JM, Powell KE, Kraus WE, Bloodgood B, Campbell WW, Dietz S, Dipietro L, George SM, Macko RF, McTiernan A, Pate RR, Piercy KL; 2018 PHYSICAL ACTIVITY GUIDELINES ADVISORY COMMITTEE. Physical Activity to Prevent and Treat Hypertension: A Systematic Review. Med Sci Sports Exerc. 2019;51(6):131423. doi: 10.1249/MSS.0000000000001943.

5. Chodzko-Zajko WJ, Proctor DN, Fiatarone Singh MA, Minson CT, Nigg CR, Salem GJ, Skinner JS. Exercise and physical activity for older adults. Med Sci Sport Exerc. 2009;41:1510-30. doi: 10.1249/MSS.0b013e3181a0c95c

6. Pate BRR, Neill JO, Dowda M, Farrell SW, O'Neill JR.. Physical Activity Guidelines for Americans. 2nd ed. Services USD of Health and Human Services, editor. Washington, DC; 2018. 1-118 p. doi: 10.1161/CIRCOUTCOMES.118.005263

7. Tulloch H, Sweet SN, Fortier M, Capstick G, Kenny GP, Sigal RJ. Exercise facilitators and barriers from adoption to maintenance in the diabetes aerobic and resistance exercise trial. Can J Diabetes. 2013;37(6):367-74. doi: 10.1016/j.jcjd. 2013.09.002

8. Fisher JP, Steele J, Gentil P Giessing J, Westcott WL. A minimal dose approach to resistance training for the older adult; the prophylactic for aging. Exp Gerontol. 2017 Dec;99:80-6. doi: 10.1016/j.exger. 2017.09.012

9. Souza D, Barbalho M, Vieira CA, Martins WR, Cadore EL, Gentil P. Minimal dose resistance training with elastic tubes promotes functional and cardiovascular benefits to older women. Exp Gerontol. 2019 Jan;115:132-138. doi: 10.1016/j.ex ger.2018.12.001.

10. Seguro C, Viana R, Lima G, Galvão L, Silva L, Jardim T, Jardim P, Gentil P. Improvements in health parameters of a diabetic and hypertensive patient with only 40 minutes of exercise per week: a case study. Disabil Rehabil 2020 Oct;42(21):3119-3125. doi: 10.1080/09638288. 2019.1583780.

11. Cornelissen VA, Fagard RH, Coeckelberghs E, Vanhees L. Impact of resistance training on blood pressure and other cardiovascular risk factors: a meta-analysis of randomized, controlled trials. Hypertension. 2011/09/08. 2011;58(5):950-8. doi: 10.1161/HYPERTENSIONAHA.111.177071

12. Sardeli AV, Griffith GJ, dos Santos MVMA, Ito MSR, Nadruz W, Chacon-Mikahil MPT Do baseline blood pressure and type of exercise influence level of reduction induced by training in hypertensive older adults? A meta-analysis of controlled trials. Exp Gerontol. 2020 Oct;140. doi: 10.1016/j.exger.2020.111052.

13. Artero EG, Lee DC, Ruiz JR, Sui X, Ortega FB, Church TS, Lavie CJ, Castillo MJ, Blair SN. A prospective study of muscular strength and allcause mortality in men with hypertension. J Am Coll Cardiol. 2011/04/30. 2011;57(18):1831-7. doi: 10.1016/j.jacc.2010.12.025.

14. Vera-Cala LM, Orostegui M, Valencia-Angel LI, López N, Bautista LE.. Accuracy of the Omron HEM-705 CP for blood pressure measurement in large epidemiologic studies. Arq Bras Cardiol. 2011 May;96(5):393-8. doi: 10.1590/s0066-782x20110 05000038.

15. Malachias MVB, Gomes MAM, Nobre F, Alessi A, Feitosa AD, Coelho EB. 7th Brazilian Guideline of Arterial Hypertension: Chapter 2 - Diagnosis and Classification. Arq Bras Cardiol. 2016 Sep;107(3 Suppl 3):7-13. doi: 10.5935/abc.20160152.

16. Steele J, Fisher J, Giessing J, Gentil P. Clarity in reporting terminology and definitions of set endpoints in resistance training. Muscle Nerve. 2017 Sep;56(3):368-74. doi: 10.1002/mus.25557.

17. Gentil P, Bottaro M. Influence of supervision ratio on muscle adaptations to resistance training in nontrained subjects. J Strength Cond Res. 2009/08/08. 2010;24(3):639-43. doi: 10.1519/ JSC.0b013e3181ad3373.

18. Paoli A, Gentil P, Moro T, Marcolin G, Bianco A. Resistance training with single vs. multi-joint exercises at equal total load volume: Effects on body composition, cardiorespiratory fitness, and muscle strength. Front Physiol. 2017;8(DEC). doi: 10.3389/fphys.2017.01105.

19. Gentil P, Steele J, Fisher J. Why intensity is not a bad word - Benefits and practical aspects of high effort resistance training to the older. Clin Nutr. 2017 Oct;36(5):1454-5. doi: 10.1016/j.clnu.2017 .05 .024 .

20. Cucato GG, Lima AHRA, Cavalcante BR, SobralFilho DC, Ritti-Dias RM. Effects of resistance training on cardiovascular function in patients with peripheral artery disease: A randomized controlled 
trial. J Strength Cond Res. 2018;32(4):1072-80. doi: 10.1519/JSC.0000000000001914.

21. Whelton PK, Carey RM, Aronow WS, Casey DE Jr, Collins KJ, Dennison Himmelfarb C, DePalma SM, Gidding S, Jamerson KA, Jones DW, MacLaughlin EJ, Muntner P, Ovbiagele B, Smith SC Jr, Spencer CC, Stafford RS, Taler SJ, Thomas RJ, Williams KA Sr, Williamson JD, Wright JT Jr. 2017 ACC/AHA/AAPA/ABC/ACPM/ AGS/APhA/ASH /ASPC/NMA/PCNA Guideline for the Prevention, Detection, Evaluation, and Management of High Blood Pressure in Adults: A Report of the American College of Cardiology/American Heart Association Task Force on Clinical Practic. J Am Coll Cardiol. 2018;71(19):e127-248. doi: 10.1161/HYP.000000 0000000066.

22. Li Y, Wei FF, Thijs L, Boggia J, Asayama K, Hansen TW, Kikuya M, Björklund-Bodegård K, Ohkubo T, Jeppesen J, Gu YM, Torp-Pedersen C, Dolan E, Liu YP, Kuznetsova T, Stolarz-Skrzypek K, Tikhonoff V, Malyutina S, Casiglia E, Nikitin Y, Lind L, Sandoya E, Kawecka-Jaszcz K, Mena L, Maestre GE, Filipovský J, Imai Y, O'Brien E, Wang JG, Staessen JA; International Database on Ambulatory blood pressure in relation to Cardiovascular Outcomes (IDACO) Investigators. Ambulatory hypertension subtypes and 24-hour systolic and diastolic blood pressure as distinct outcome predictors in 8341 untreated people recruited from 12 populations. Circulation. 2014;130(6):466-74. doi: 10.1161/CIRCULA TIONAHA.113.004876.

23. Lewington S, Clarke R, Qizilbash N, Peto R, Collins R; Prospective Studies Collaboration. Agespecific relevance of blood pressure to causespecific mortality is best assessed by collaborative meta-analysis of individual participant data from the separate prospective studies. Lancet. 2002;360:1903-13. doi: 10.1016/s0140-6736(02) 11911-8.

24. Gjøvaag TF, Mirtaheri P, Simon K, Berdal G, Tuchel I, Westlie T, Bruusgaard KA, Nilsson BB, Hisdal J. Hemodynamic responses to resistance exercise in patients with coronary artery disease. Med Sci Sports Exerc. 2016;48(4):581-8. doi: 10.1249/MSS.0000000000000811.

25. Fleck SJ, Dean LS. Resistance-training experience and the pressor response during resistance exercise. J Appl Physiol. 1987/07/01. 1987;63(1):116-20. doi: 10.1152/jappl.1987.63.1.116.

26. Lamotte M, Niset $G$, van de Borne P. The effect of different intensity modalities of resistance training on beat-to-beat blood pressure in cardiac patients. Eur J Cardiovasc Prev Rehabil. 2005/02/11.
2005;12(1):12-7. doi: 10.1097/01.hjr.0000159275. 96437.c7.

27. Vale AF, Carneiro JA, Jardim PC V, Jardim TV, Steele J, Fisher JP, Gentil P. Acute effects of different resistance training loads on cardiac autonomic modulation in hypertensive postmenopausal women. J Transl Med. 2018 Aug;16(1):240. doi: 10.1186/s12967-018-1615-3.

28. Gentil P, Soares SR, Pereira MC, da Cunha RR, Martorelli SS, Martorelli AS, Bottaro M. Effect of adding single-joint exercises to a multi-joint exercise resistance-training program on strength and hypertrophy in untrained subjects. Appl Physiol Nutr Metab. 2013/03/30. 2013;38(3):341-4. doi: 10.1139/apnm-2012-0176.

29. de França HS, Branco PA, Guedes Junior DP, Gentil P, Steele J, Teixeira CV. The effects of adding single-joint exercises to a multi-joint exercise resistance training program on upper body muscle strength and size in trained men. Appl Physiol Nutr Metab. 2015/08/06. 2015;40(8):8226. doi: 10.1139/apnm-2015-0109.

30. Gentil P, Fisher J, Steele J. A Review of the Acute Effects and Long-Term Adaptations of Single- and Multi-Joint Exercises during Resistance Training. Sport Med. 2017;47(5):843-55. doi: 10.1007/ s40279-016-0627-5.

31. Arazi H, Asadi A, Alipour V. Blood pressure responses to resistive exercise in trained female athletes: Infl uence of velocity of movement. Interv Med Appl Sci. 2014;6(4):170-4. doi: 10.1556/ IMAS.6.2014.4.5

32. Barbalho MSM, Gentil P, Izquierdo M, Fisher J, Steele J, Raiol RA. There are no no-responders to low or high resistance training volumes among older women. Exp Gerontol. 2017 Sep;99(12):1826. doi: 10.1016/j.exger.2017.09.003.

33. Abrahin O, Rodrigues RP, Nascimento VC, Da Silva-Grigoletto ME, Sousa EC, Marçal AC. Single- and multiple-set resistance training improves skeletal and respiratory muscle strength in elderly women. Clin Interv Aging. 2014;9:177582. doi: $10.2147 /$ CIA.S68529.

34. Piercy KL, Troiano RP, Ballard RM, Carlson SA, Fulton JE, Galuska DA, George SM, Olson RD. The physical activity guidelines for Americans. JAMA - J Am Med Assoc. 2018;320(19):2020-8. doi: 10.1001/jama.2018.14854.

Submission: December 4, 2020

Revision received: January 4, 2021 Accepted for publication: January 5, 2021 